\title{
ESTHETIC TREATMENT OF HYPERPIGMENTED GINGIVA BY SCALPEL AND LASER: A COMPARATIVE CASE REPORT
}

\author{
Dr.Indumathi P, Dr.Ramakrishnan.T, Dr.Dhivya R, Dr.Shivaranjani.P, Dr.Irudhaya Nirmala.J \\ Department of Periodontology, Adhi Parasakthi Dental College \& Hospital, Melmaruvathur, Tamilnadu, India.
}

\section{To access \& cite this article}

\section{Website: jidam.idamadras.com}

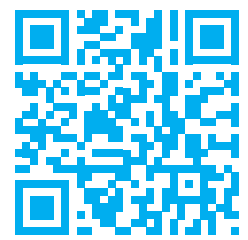

DOI:10.37841/jidam 2020 V7 I2 04

\section{Address for correspondence:}

Dr. Indumathi.P

Post Graduate, Department of Periodontology, Adhi Parasakthi Dental College \& Hospital, Melmaruvathur, Tamilnadu, India. Email id: indukutty523@gmail.com

$\begin{array}{ll}\text { Received } & : 27.03 .2020 \\ \text { Accepted } & : 17.05 .2020 \\ \text { Published } & : 27.06 .2020\end{array}$

\section{ABSTRACT}

BACKGROUND: Melanin pigmentation in the gingiva occurs as a result of excess deposition of melanin, due to which the gingiva appears black. Many people complain of dark gums as unesthetic. Gingiva is the most frequently pigmented intraoral tissue, more pigmentation concentrated in the incisor region which may interfere with the smile line and patient may feel conscious about the appearance. In such patients, esthetic periodontal plastic surgery can give excellent results.

CASE REPORT: In this case report we have attempted and compared, two different depigmentation techniques using a semi-conductor diode laser technique in maxillary anterior arch and conventionally by scalpel technique in mandibular anterior arch.

RESULT: Both scalpel and laser improved esthetics. However the laser treatment resulted in no post-operative bleeding and no post-operative pain as compared with scalpel technique.

CONCLUSION: Use of diode laser is the safe and effective alternative procedure for the treatment of hyperpigmented gingiva. Its benefits include ease of usage, comfort in dental clinics, reduce trauma to the patient.

KEYWORDS: Diode laser, Depigmentation, Melanin pigment. 


\section{INTRODUCTION:}

The gingival color is determined by various factors such as blood vessels, epithelial thickness, keratinization quantity and presence of pigments within the gingival epithelium ${ }^{1}$. The color of attached and marginal gingiva is generally described as coral pink ${ }^{2}$. Melanin is a brown pigment, the most common natural pigment contributing to endogenous pigmentation of the gingiva ${ }^{3}$. Melanin pigmentation is the result of melanin granules produced by melanoblasts interwined between epithelial cells and basal layer of gingival epithelium ${ }^{4}$. Pigmentation of the gingiva occur in all ethinicities ${ }^{5}$. But high levels of oral pigmentation are observed in individuals of African and East Asian. The distribution of pigmentation in oral cavity in black individuals is as follows: gingiva $60 \%$, hard palate $61 \%$, mucous membrane $22 \%$ and tongue $15 \%$. Gingival pigmentation occurs as a diffuse, irregularly shaped brown to light-brown patch. It may appear in the gingiva as early as 3 hours after birth. Pigmentation of gingiva can caused by local and systemic factors such as antimalarial therapy, malignant melanoma, Peutz- Jeghers syndrome, Albright's syndrome, trauma, endocrine disturbances hemachromatosis, chronic pulmonary disease and racial pigmentation are the identified causes of oral melanin pigmentation $^{6}$. The gingival hyperpigmentation is treated by various techniques and the selection of technique based on clinical experiences and individual preferences with demand for improved esthetics. Different techniques for depigmentation include $^{7}$ :

1. Scalpel

2. Cryosurgery

3. Electrosurgery

4. Chemical method

5. Masking the pigmented gingiva

a. Free gingival graft

b. Acellular dermal matrix allograft

6. Lasers - Nd: YAG laser, Er: YAG laser, CO2 laser

Recently, laser ablation has been recognized as a most effective, pleasant and reliable technique.

The present case series describes a comparative evaluation of treating gingival pigmentation using scalpel and diode laser technique.

\section{CASE REPORT:}

A 23 years old male patient reported to the Department of Periodontology, Adhiparasakthi Dental College and Hospital with the chief complaint of black discoloration of his gums since he was very concerned about the esthetic appearance. Intraoral examination revealed no dental abnormalities other than pigmentation in maxillary and mandibular gingiva (Fig 1). The pigmentation was displeasing for the patient so a treatment plan of depigmentation was proposed. After obtaining patient's consent, treatment was initiated. Phase I therapy included routine blood investigation and as all values were within physiological limits, scaling was done and the patient was recalled after a week for depigmentation procedure.

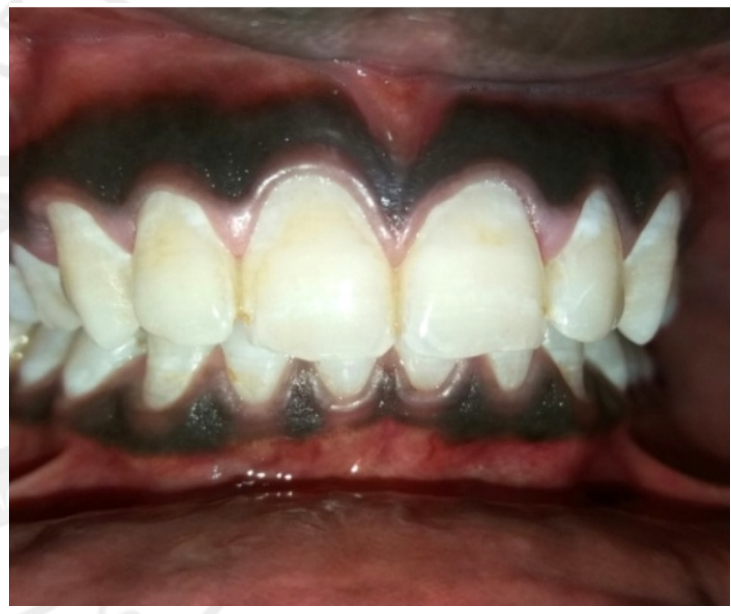

Fig 1: Preoperative view

PROCEDURE:

\section{DEPIGMENTATION WITH LASER:}

After application of topical anesthesia (Lignocaine 2\% gel) on maxillary anterior region, the diode laser with power settings of 1-1.5 watts with continuous mode was used to remove the pigmented epithelium (Fig 2). The laser tip was used with brushing strokes and high volume suction was used to evacuate the laser plumes. Tissue tags were removed using wet gauze (Fig 3). During the procedure, patient, surgeon and assistant were advised to wear protective eyewear to fulfill the FDA measures. Patient was comfortable from the beginning till the end of the treatment. Post operative instructions were given and patient was recalled after $7^{\text {th }}$ and $15^{\text {th }}$ day for review (Fig 4). 


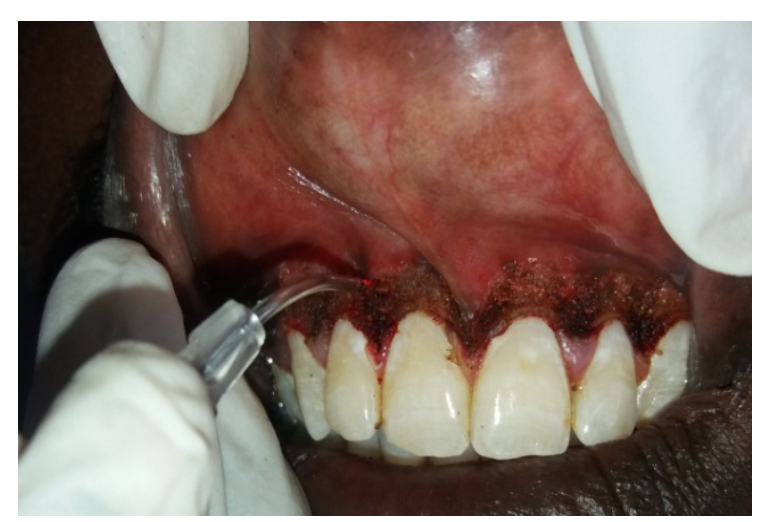

Fig 2 : Use of diode laser

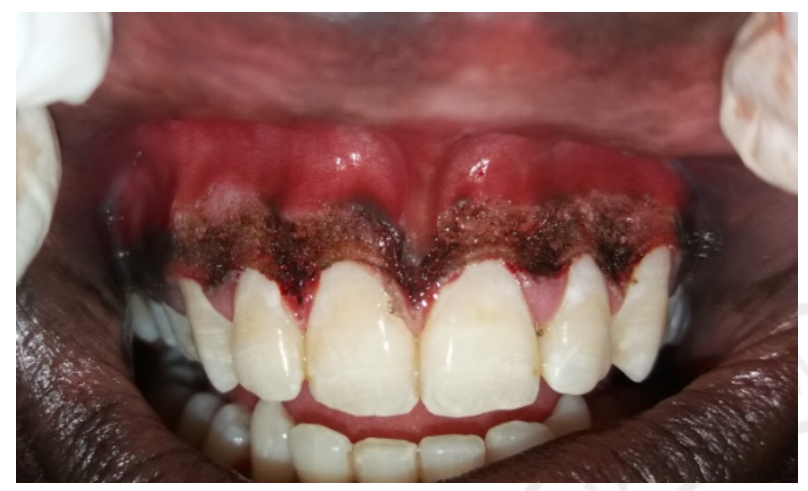

Fig 3: Immediate post operative view

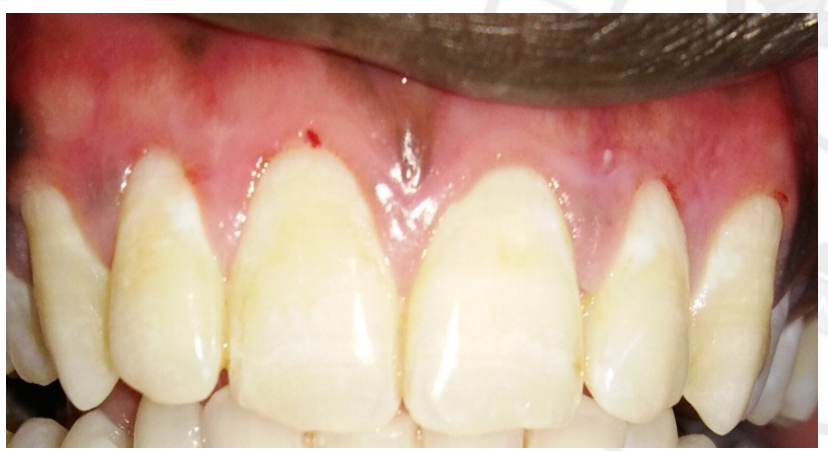

Fig 4: Post operative view after 15 days

\section{DEPIGMENTATION WITH SCALPEL TECHNIQUE:}

After infiltration of local anesthesia in the mandibular anterior region, depigmentation was done using scalpel method. Depigmentation was carried out from the mucogingival junction to the interdental papilla with BP blade No 15 (Fig 5). Care was taken to avoid pitting of gingival surface or to remove excess tissue. The entire pigmented epithelium was removed and was ensured that of pigmented layer were removed (Fig 6), pressure was applied with a sterile gauze moistened with saline to control bleeding. Thorough saline irrigation was done and the surgical area was covered with periodontal dressing (Fig 7). Post surgical antibiotics and analgesics were prescribed along with the chlorhexidine mouth wash. The patient was recalled after $7^{\text {th }}$ and $15^{\text {th }}$ day for review (Fig 8).

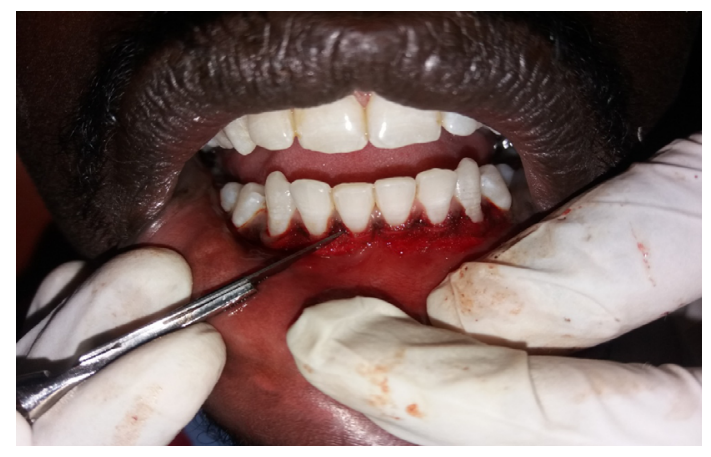

Fig 5: Use of Scalpel technique

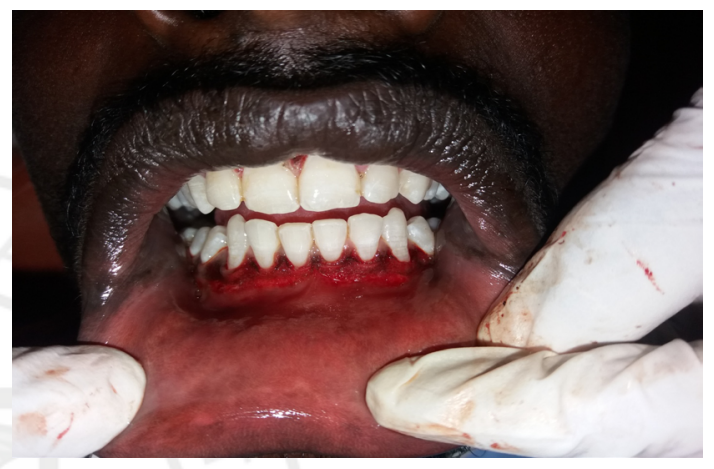

Fig 6: Immediate postoperative view

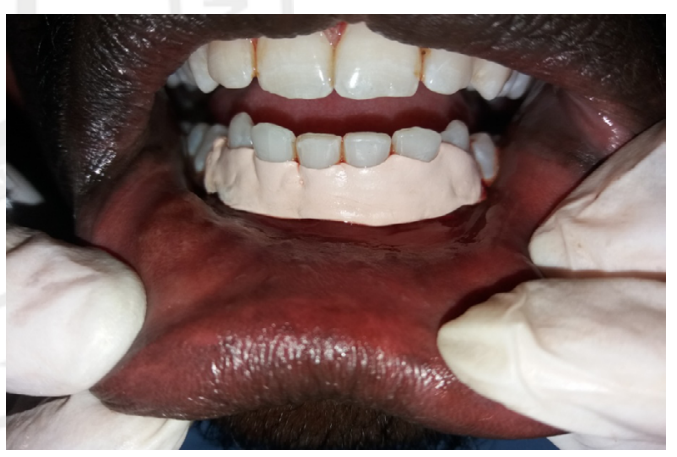

Fig 7: Surgical site covered with periodontal dressing

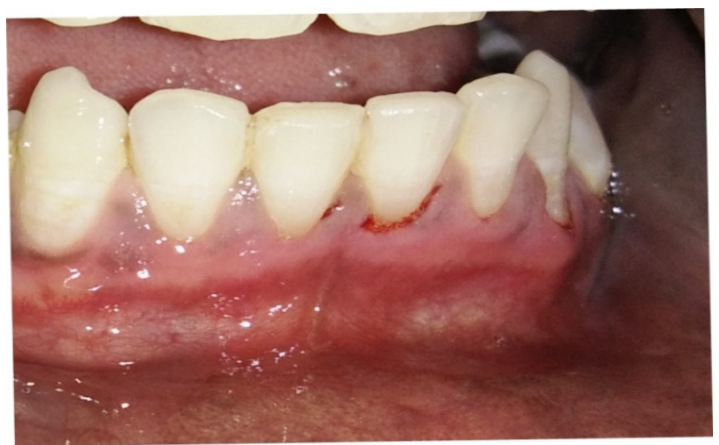

Fig 8: Post operative view after 15 days

Patient was reviewed on $7^{\text {th }}$ and $15^{\text {th }}$ day and VAS were recorded to compare between laser method and scalpel method pre and post operatively (Fig 9 and Fig 10). 
Clinical evaluation of pain visual analog scale:

\begin{tabular}{|l|c|c|c|}
\hline Method & $\begin{array}{c}\text { Immediate } \\
\text { post op }\end{array}$ & $\begin{array}{c}\text { Postop }- \\
1 \text { day }\end{array}$ & $\begin{array}{c}\text { Postop } \\
-15 \text { days }\end{array}$ \\
\hline Surgical & 2 & 4 & 1 \\
\hline Laser & 1 & 2 & 0 \\
\hline
\end{tabular}

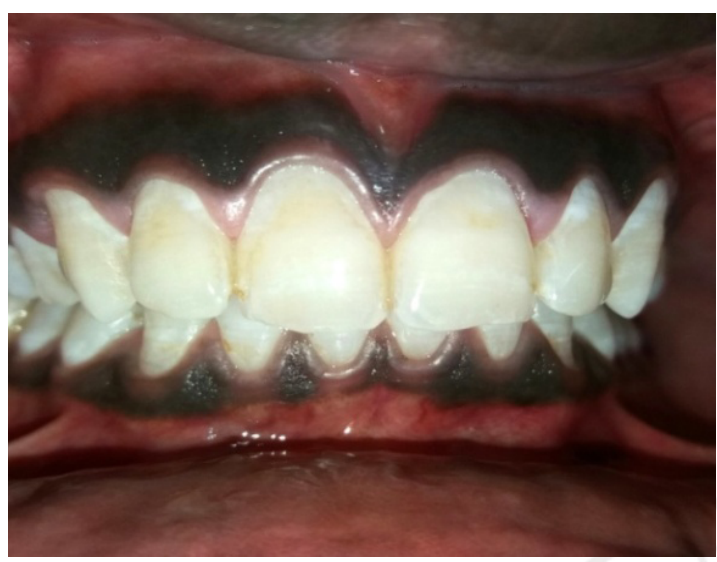

Fig 9 : Pre operative view

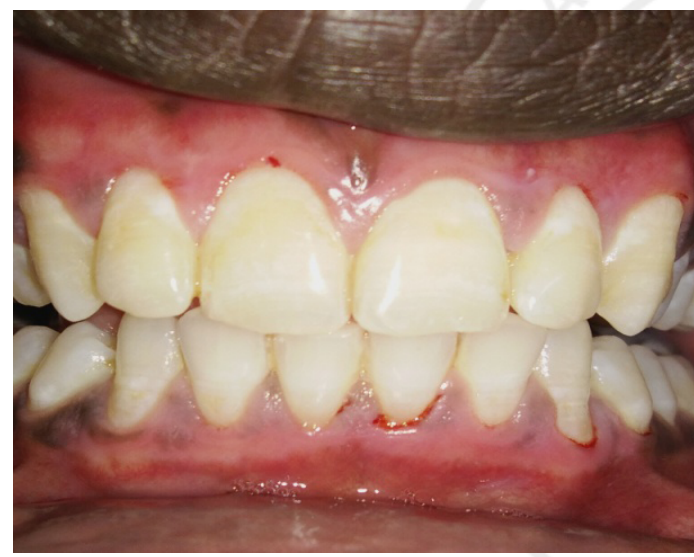

Fig 10: Post operative view

\section{DICUSSION:}

Melanin pigmentation is frequently caused by melanin deposition by active melanocytes ${ }^{8}$. Pigmented gingival tissue often forces patient to seek cosmetic treatment. Several techniques have been suggested for treating the gingival pigmentation. In this present case report, both the scalpel and laser technique was used. To date numerous lasers systems are available for both soft and hard tissue, like neodymium-doped yttrium-aluminum-garnet (Nd:YAG) carbon dioxide (CO2), semiconductor diode lasers, erbium-doped yttrium-aluminum-garnet (Er:YAG) laser ${ }^{9}$. The semiconductor diode laser is emitted in continuous wave or gated pulse mode and usually operated in a contact method by using flexible fiber optic delivery system. Laser light at $800-980 \mathrm{~nm}$ is poorly absorbed in water but highly absorbed in hemoglobin and other pigments. The diode laser is an excellent soft tissue laser indicated for cutting, coagulating gingival and oral mucosa and for soft tissue curettage or sulcular debridement. The diode laser exhibits thermal effect using the "hot tip" effect caused by heat accumulation at the end of the fiber, and produces a relatively thick coagulation layer on the treated surface, it does not produce any harmful effect on root surface ${ }^{10}$. There are many advantages of lasers over surgical procedures. According to Wigdor et al (1995) these include:

- $\quad$ Dry and bloodless surgery

- Instant sterilization of the surgical site

- $\quad$ Reduced bacteremia

- $\quad$ Reduced mechanical trauma

- Minimal postoperative swelling and scar Minimal postoperative pain

The use of lasers can reduce patients anxiety or fear of drill. It provides a 'needle-free' approach or no anesthesia dentistry. Also, laser dentistry requires less chair-side time compared to more traditional treatments. The diode laser has the unique property of being able to remove a thin layer of epithelium cleanly and it causes minimal damage to periosteum and bone under the gingiva being treated ${ }^{11}$. In this present case report the laser technique found to be effective than the scalpel technique, since the patient has less post operative pain and discomfort in the site treated by diode laser which was proved by VAS score. However the healing period of scalpel wound is shorter than with diode laser, it causes unpleasant bleeding during and after the procedure and it is necessary to cover the surgical site with periodontal pack .

\section{CONCLUSION:}

Gingival depigmentation is most often a patient demanded esthetic treatment. In this current case report, both scalpel and laser was found to be effective in the treatment of gingival hyperpigmentation, however laser being more patient friendly. Thus laser ablation for gingival depigmentation has been recognized as one of the most effective, pleasant and reliable techniques ${ }^{9}$ that offers bloodless, painless, and sterile field with better patient compliance and satisfaction. 
FINANCIAL SUPPORT AND

SPONSORSHIP:

Nil

\section{CONFLICTS OF INTEREST:}

There are no conflicts of interest.

\section{REFERENCES :}

1. Kathariya R, Pradeep AR. Split mouth de-epithelization techniques for gingival depigmentation: A case series and review of literature. Journal of Indian Society of Periodontology. 2011 : 15(2):161.

2. Newman MG, Takei H, Klokkevold PR, Carranza FA. Carranza's clinical periodontology. Elsevier health sciences; 2011:14.

3. Grover HS, Dadlani H, Bhardwaj A, Yadav A, Lal S. Evaluation of patient response and recurrence of pigmentation following gingival depigmentation using laser and scalpel technique: A clinical study. Journal of Indian Society of Periodontology. 2014;18(5):586.

4. Patil KP, Joshi V, Waghmode V, Kanakdande V. Gingival depigmentation: A split mouth comparative study between scalpel and cryosurgery. Contemporary clinical dentistry. $2015 ; 6$.

5. Ladvige S, Doshi Y, Marawar P. Management of gingival hyperpigmentation using scalpel and diode laser: A comparative study. J Oral Laser Appl. 2009;9:41-7.

6. Renganath MJ, Ramakrishnan T, VidyaSekhar $\mathrm{MN}$, Ebenezer M, Anithadevi S. Black to Pink: A Case Report of Treating Gingival Hyperpigmentation. Int J Cur Res Rev 2017 1;9(3):14.

7. Murthy MB, Kaur J, Das R. Treatment of gingival hyperpigmentation with rotary abrasive, scalpel, and laser techniques: A case series. Journal of Indian Society of Periodontology. 2012 ;16(4):614.

8. Kaushik N, Srivastava N, Kaushik M, Gaurav V. Efficacy of different techniques of gingival depigmentation: a comparative evaluation with a case report. Int $\mathrm{J}$ Laser Dent. 2013;3(2):68-72.

9. Bhardwaj A, Grover HS, Lal S. Gingival depigmentation with scalpel and diode laser. World journal of dentistry. 2012 ;3(4):359-62.

10. Bakutra G, Shankarapillai R, Mathur L, Manohar B. Comparative evaluation of diode laser ablation and surgical stripping technique for gingival depigmentation: A clinical and immunohistochemical study. International journal of health sciences. $2017 ; 11(2): 51$.

11. Sanadi DR, Suthar DN, Bhusari DB, Chelani DL. Gingival Depigmentation Using Scalpel Technique versus Laser Technique: A Case Report. IOSR Journal of Dental and Medical Sciences. 2015 :2279-0853. 